\title{
Residual Efficacy of Fungicides for Controlling Brown Patch on Creeping Bentgrass Fairways
}

John P. Daniels and Richard Latin, Department of Botany and Plant Pathology, Purdue University, West Lafayette, IN 47907-2054

\begin{abstract}
Daniels, J. P., and Latin, R. 2013. Residual efficacy of fungicides for controlling brown patch on creeping bentgrass fairways. Plant Dis. 97:16201625.

Residual efficacy of five fungicides (azoxystrobin, flutolanil, metconazole, polyoxin $\mathrm{D}$, and pyraclostrobin) applied to creeping bentgrass (Agrostis stolonifera) maintained under golf course fairway conditions was determined using a bioassay method. During 2010 and 2011, six different field experiments were conducted. Each consisted of a single fungicide application followed by periodic $(0,3,7,10,14,17$, and 21 days after application) turf sampling, inoculation of samples with an isolate of Rhizoctonia solani, and incubation in a controlled environment chamber for $48 \mathrm{~h}$. For each sample date, fungicide efficacy was determined by measuring the extent of symptom expansion on fungicide treated and nontreated samples. Efficacy half-life values based on a two-parameter Weibull function were 3.1 to 14.0 days for the fungi-

cides used in this study. Residual efficacy was further examined in 2011 by analyzing residues from creeping bentgrass verdure using liquid chromatography/time-of-flight mass spectrometry (LC/TOFMS). Quantitative analysis from LC/TOF-MS revealed that fungicide residues were depleted rapidly following application to turfgrass and reinforced the precipitous decline in fungicide efficacy demonstrated by the bioassays. Regardless of fungicide, more than $90 \%$ of active ingredient applied was depleted from the verdure between 3 and 8 days after application, and more than $99 \%$ of fungicide was depleted at 17 days after application. This research provides a quantitative description of the temporal nature of loss of fungicide and fungicide protection from turf.
\end{abstract}

Brown patch, caused by Rhizoctonia solani Kühn, is a foliar disease of cool-season turfgrass that often occurs during periods of warm, humid weather. Damage resulting from brown patch outbreaks reduces the aesthetic value of amenity turf. In golf course settings, thinned areas of blighted turf negatively impact playability by disrupting ball lie and roll characteristics. Although numerous practices $(2,4,5,18)$ may reduce severity of brown patch outbreaks, golf course superintendents continue to rely on repeated applications of fungicides to insure adequate control on greens, tees, and fairways. Numerous effective fungicides are registered for brown patch control; they typically are applied at 7- to 28-day intervals, as recommended by product labels, during periods conducive to disease development (14).

Once a fungicide is applied to the turf canopy, a combination of abiotic and biotic factors influence its persistence. Depletion of fungicide residues can result from runoff and leaching during rainfall or irrigation events, volatilization, removal of clippings during mowing, photolysis, microbial degradation, and enzymatic breakdown in the plant $(8,10,16,17,20-23)$. Fungicide depletion is a concern because it exposes turfgrass to the possibility of brown patch outbreaks during periods of weather that favor pathogen development.

Previous studies on the persistence of fungicides applied to turf environments $(3,6-9,11,17,19,20,22,23)$ primarily focused on issues concerning environmental fate. Frederick et al. (6) noted a rapid degradation of triadimefon within the first 7 days during a laboratory study on fungicide persistence in Kentucky bluegrass (Poa pratensis L.) clippings. A similar trend was observed in a field study where vinclozolin was applied to creeping bentgrass (Agrostis stolonifera L.) (7). Horst et al. (11) demonstrated that pesticide residues, including the fungicide metalaxyl, can be reduced in fairway-height Kentucky bluegrass leaf tissue by as much

Corresponding author: R. Latin, E-mail: rlatin@purdue.edu

Accepted for publication 28 June 2013.

http://dx.doi.org/10.1094/PDIS-12-12-1130-RE

(C) 2013 The American Phytopathological Society as $82 \%$ in 7 to 10 days. Likewise, 71 to $80 \%$ of cyproconazole residues were dissipated from fairway-height creeping bentgrass verdure 4 days following application (9). Results of another field study on fairway-height creeping bentgrass estimated half-lives of 5 to 6 and 12 to 15 days for mefenoxam and propiconazole, respectively (8). Also, on greens-height creeping bentgrass, shorter half-lives were calculated for metalaxyl and chlorothalonil (23). Furthermore, Sigler et al. (19) estimated creeping bentgrass canopy half-lives of 3.3, 3.7, and 3.6 days for triadimefon, metalaxyl, and iprodione, respectively. Although these reports describe fungicide dissipation from turfgrass, they do not address any implications with regard to disease control.

Information on the depletion of fungicide residues over the course of a typical application interval and how that impacts fungicide performance under high disease pressure (i.e., ideal environmental conditions for the pathogen) is limited. A bioassay technique using the dollar spot pathogen (Sclerotinia homoeocarpa) as the test organism showed significant reductions in residual efficacy over the course of a 21-day spray interval (13). For all fungicides tested, a precipitous decline in efficacy occurred after 7 days. Halflife estimates based on efficacy varied from 6.1 to 9.5 days for propiconazole, iprodione, thiophanate-methyl, chlorothalonil, and mancozeb (13).

In the present study, we investigated fungicide persistence within the turf canopy in an effort to understand the temporal nature of fungicide performance against the brown patch disease. Our objective was to describe and quantify the residual efficacy of fungicides applied to creeping bentgrass for control of brown patch on golf course fairways.

\section{Materials and Methods}

Management practices. Field research was conducted at the Daniel Turfgrass Research and Diagnostic Center in West Lafayette, IN, during fall 2010, summer 2011, and fall 2011. A mature stand of creeping bentgrass ('Penneagle') that had no recent fungicide history was used for all experiments. The site was maintained according to standard turf maintenance practices for fairway-height creeping bentgrass in the Midwest. Turf was mowed at a cutting height of $1.3 \mathrm{~cm}$ with a 5-plex reel mower three mornings per week (Monday, Wednesday, and Friday), with clippings returned to the 
turf. Irrigation was applied as needed to prevent drought stress. Total annual application of nitrogen, phosphorous, and potassium were 134,12 , and $67 \mathrm{~kg} \mathrm{ha}^{-1}$, respectively. Aerification was accomplished using $1.6 \mathrm{~cm}$-diameter hollow-tines (5-by-5-cm spacing) during the spring and fall, before and after the experimental period.

Fungicide application. Five commonly used fungicides for controlling brown patch on golf courses were selected for this research and were applied at labeled rates according to manufacturer recommendations (Table 1). They included azoxystrobin (Heritage TL; Syngenta Crop Protection), flutolanil (Prostar 70 WP; Bayer Environmental Sciences), metconazole (Valent U.S.A. Corporation), polyoxin D (Endorse WP; Cleary Chemical Company), and pyraclostrobin (Insignia; BASF Corporation). The selected fungicide active ingredients vary in phytomobility and mode of action (14). Azoxystobin is an acropetal penetrant that interferes with mitochondrial electron transport at Complex III, flutolanil is an acropetal penetrant which disrupts mitochondrial electron transport at Complex II, metconazole is an acropetal penetrant that hinders ergosterol biosynthesis, polyoxin D is a local penetrant which prevents chitin synthesis, and pyraclostrobin is a local penetrant that impedes mitochondrial electron transport at Complex III (14).

Fungicide treatments, including an untreated control, were arranged in a randomized complete block design with four replications. Individual treatment plots measured 1 by $2 \mathrm{~m}$ and replications were separated by $2-\mathrm{m}$ untreated buffers. Fungicides were applied once at the initiation of each experiment with a custombuilt $\mathrm{CO}_{2}$ pressured sprayer equipped with three air-induction flat spray tips (TeeJet Technologies) that were mounted approximately $38 \mathrm{~cm}$ apart and $41 \mathrm{~cm}$ from the ground. The sprayer was calibrated to deliver 815 liters ha ${ }^{-1}$. Fungicide treatments were applied in the late morning (1000 to $1200 \mathrm{~h}$ ) after mowing was complete. Studies were initiated 17 September 2010, 12 October 2010, 8 June 2011, 22 June 2011, 6 July 2011, and 26 August 2011. One week prior to the application of treatments, the entire sward was treated with boscalid (Emerald; BASF Corporation) at $0.384 \mathrm{~kg}$ a.i. $\mathrm{ha}^{-1}$ to suppress $S$. homoeocarpa and mefenoxam (Subdue MAXX; Syngenta Crop Protection) at $0.763 \mathrm{~kg}$ a.i. $\mathrm{ha}^{-1}$ to suppress activity of Pythium spp. These fungal contaminants could interfere with $R$. solani development during the incubation period and, therefore, were selectively controlled.

Bioassay experiment. Following application of treatments, 10.8-cm-diameter turf samples were periodically removed from the center of each plot using a lever action hole cutter (Par Aide Products Co.). Samples were collected during the afternoon on the day treatments were applied (day 0) and 3, 7, 10, 14, 17, and 21 days after application. Turf samples were then inoculated with $R$. solani (Purdue University isolate RZ0104) growing on previously sterilized white sorghum seed. Fresh inoculum was prepared 1 week prior to the start of each experimental run. Four infested grains were placed in the center of each turf sample. Samples were incubated in a dew chamber (I-36DL; Percival Scientific, Inc.) at $30^{\circ} \mathrm{C}$ and $>95 \%$ relative humidity for $48 \mathrm{~h}$. Disease development was determined by measuring and recording the symptomatic patch diameters. Measurements were used to calculate a residual efficacy (RE) proportion based on the formula $\mathrm{RE}=1-$ (patch diameter of fungicide treated turf/patch diameter of untreated turf).

Bioassay RE proportions were subjected to arcsine square root transformation for better approximation to normal distribution prior to analysis of variance (ANOVA) and mean separation using Tukey's honestly significant difference (HSD) test $(P=0.05)$ in
Statistica (version 7.1; StatSoft, Inc.). Results from repeated experiments were combined where homogeneity of variance was observed. RE data demonstrated a sigmoidal shape and required a model that could capture two inflection points. A two-parameter Weibull distribution function of $\mathrm{RE}=1 /\left[1+e^{(\alpha+\beta t)}\right]$ was selected to describe the decline in RE over time $(t)$. Nonlinear estimation was performed using the Levenberg-Marquardt algorithm in Statistica to obtain parameter estimates $(\alpha, \beta)$. Because residual efficacy proportion cannot exceed a value of 1.0 (i.e., $100 \%$ efficacy) or be less than 0.0 (i.e., $0 \%$ efficacy), the selected function reached horizontal asymptotes at 1.0 and 0.0. Models from each experiment were used to determine efficacy half-life values, which represent the length of time in days for efficacy to be reduced to $50 \%$. Efficacy half-life calculations for each fungicide were compared by ANOVA and Tukey's HSD test.

Quantitative residue analysis. During 2011, additional turf samples were collected from the same experimental plots of the bioassay to further investigate the persistence of the selected fungicides applied to creeping bentgrass under fairway conditions. Sampling followed the same schedule (day 0,3, 7, 10, 14, 17, and 21) as the bioassay. Fungicide residues were identified and quantified by liquid chromatography/time-of-flight mass spectrometry (LC/TOF-MS). All fungicides were analyzed using this technique, with the exception of polyoxin D. Polyoxin D analytical standard could not be secured in 2011 and, therefore, is absent from the quantitative residue analysis.

Data from LC/TOF-MS followed first-order kinetics and were fit to the equation $X=A e^{-k t}$ described by Frederick et al. (6), where $X$ is the concentration $\left(\mu \mathrm{g} \mathrm{g}^{-1}\right)$ of fungicide, $A$ is the initial concentration recovered $\left(\mu \mathrm{g} \mathrm{g}^{-1}\right), k$ is the decay rate constant, and $t$ is time $\left(\right.$ days $\left.^{-1}\right)$. Decay rates $(k)$ for azoxystrobin, flutolanil, metconazole, and pyraclostrobin were determined following nonlinear curve fitting using the Levenberg-Marquardt algorithm in Statistica. Fungicide residual half-life values were computed from the formula $t_{1 / 2}=\ln (2) / k$.

Fungicide standards and reagents. The analytical fungicide standards-azoxystrobin (99.9\%), flutolanil (99.5\%), metconazole (99.5\%), myclobutanil (99.5\%), and pyraclostrobin (99.9\%)—were acquired from Sigma-Aldrich. Individual stock solutions of the above analytes at $100 \mathrm{mg} \mathrm{ml}^{-1}$ were prepared in pure acetone (flutolanil, myclobutanil, and pyraclostrobin), ethyl acetate (azoxystrobin), or methanol (metconazole) and kept in microcentrifuge polypropylene tubes at $-20^{\circ} \mathrm{C}$. For instrument calibration, working standard solution mixtures of azoxystrobin, flutolanil, metconazole, and pyraclostrobin were serial diluted in acetone and also stored at $-20^{\circ} \mathrm{C}$. High-performance liquid chromatography (HPLC)-grade acetone, acetonitrile, ammonium acetate, ethyl acetate, and methanol along with reagent-grade anhydrous magnesium sulfate and sodium acetate were obtained from Sigma-Aldrich. Dispersive solid-phase extraction (d-SPE) 15-ml tubes containing $150 \mathrm{mg}$ of primary-secondary amine (PSA) sorbent, $45 \mathrm{mg}$ of graphitized carbon black (GCB), and $855 \mathrm{mg}$ of magnesium sulfate were purchased from Agilent (Agilent Technologies). A PURELAB Ultra water system from ELGA was used to obtain HPLCgrade water for the analyses. Turf samples were homogenized with an Ultra-Turrax T8 from IKA.

Sample preparation and extraction. Turf samples $(10.8 \mathrm{~cm}$ in diameter) were collected from experimental plots as described previously, and verdure was removed using scissors. A representative portion of verdure $(0.5 \pm 0.02 \mathrm{~g}$ of leaves, shoots, and stems $)$

Table 1. Fungicides applied to creeping bentgrass in 2010 and 2011

\begin{tabular}{lllc}
\hline Fungicide & \multicolumn{1}{c}{ Group name } & Phytomobility & Rate $\left(\mathbf{k g} \text { a.i. ha }^{-\mathbf{1}}\right)^{\mathbf{z}}$ \\
\hline Azoxystrobin & Quinone outside inhibitor (QoI) & Acropetal penetrant & 0.610 \\
Flutolanil & Succinate dehydrogenase inhibitor (SDHI) & Acropetal penetrant & 4.699 \\
Metconazole & Demethylation inhibitor (DMI) & Acropetal penetrant & 0.546 \\
Polyoxin D & Polyoxin & Local penetrant & 0.305 \\
Pyraclostrobin & QoI & Local penetrant & 0.549 \\
\hline
\end{tabular}

${ }^{\mathrm{z}}$ Application rates were based on product recommendations for controlling brown patch. 
from each turf sample was weighed into a 50-ml polypropylene centrifuge tube and immediately immersed in liquid nitrogen. Samples were stored at $-80^{\circ} \mathrm{C}$ until extraction. Fungicide extraction was based on the "quick, easy, cheap, effective, rugged, and safe" (QuEChERS) method developed by Anastassiades et al. (1), with the addition of acetate buffering (AOAC Official Method 2007.01) and cleanup by d-SPE with GCB (15). GCB was included during cleanup to remove the high levels of chlorophyll found in creeping bentgrass. After thawing, $15 \mathrm{ml}$ of acetonitrile/water (80:20 [vol/vol]) was added to each centrifuge tube (D. Bartlett, Syngenta Crop Protection, personal correspondence). All samples were spiked with $10 \mu \mathrm{l}$ of myclobutanil $\left(100 \mathrm{mg} \mathrm{m}^{-1}\right)$ internal standard to insure quality control. Myclobutanil was selected as an internal standard given its structural similarities to the analytes. Turf tissue was then homogenized to generate a uniform sample extract. Magnesium sulfate $(0.4 \mathrm{~g})$ and sodium acetate $(0.1 \mathrm{~g})$ were added to each sample; centrifuge tubes were sealed and shaken vigorously for $1 \mathrm{~min}$ to break up any agglomerates. The extract was then centrifuged at 3,000 rpm for $5 \mathrm{~min}$. An 8-ml aliquot of the supernatant (acetonitrile phase) was transferred to a 15-ml d-SPE tube containing anhydrous magnesium sulfate, PSA, and GCB. After shaking vigorously for $1 \mathrm{~min}$, samples were centrifuged $(3,000 \mathrm{rpm})$ for 5 min. The supernatant $(1 \mathrm{ml})$ was then evaporated to near dryness using a vacuum concentrator. Samples were reconstituted in $200 \mu \mathrm{l}$ of methanol/water $(1: 1[\mathrm{vol} / \mathrm{vol}])$ and vortexed for $5 \mathrm{~min}$. Finally, $150 \mu \mathrm{l}$ of the sample extract was transferred into an autosampler well-plate for LC/TOF-MS analysis.

Apparatus and conditions. Selected fungicides were analyzed using an Agilent 1100 Series HPLC system, consisting of a vacuum degasser, a well-plate autosampler, and binary pumping device, coupled to an Agilent 6200 Series Accurate-Mass TOF LC/MS instrument (Agilent Technologies). Compounds were separated in a reversed-phase Zorbax SB-Phenyl column (4.6 by 150 $\mathrm{mm}, 5 \mu \mathrm{m}$ ) acquired from Agilent. Solvent A, consisting of metha$\mathrm{nol} /$ water $(20 / 80$ [vol/vol] $)$, and solvent $\mathrm{B}$, consisting of acetonitrile, both containing $5 \mathrm{mM}$ ammonium acetate $(\mathrm{pH} \mathrm{5})$, were used as mobile phases (24). Separation was performed isocractically with $45 \% \mathrm{~A} / 55 \%$ B held over $15 \mathrm{~min}$. The mobile phase flow was $0.8 \mathrm{ml} \mathrm{min}-1$ and the temperature of the column was held at room temperature. An injection volume of $10 \mu \mathrm{l}$ was used for standards and sample extracts. The MS analysis used positive polarity electrospray ionization and the source parameters were as follows: capillary voltage, $3,200 \mathrm{~V}$; nebulizer pressure, $379 \mathrm{kPa}$; drying gas, 11 liter $\mathrm{min}^{-1}$; gas temperature, $350^{\circ} \mathrm{C}$; fragmentor voltage, $100 \mathrm{~V}$; skimmer voltage, $60 \mathrm{~V}$; and octopole RF, $250 \mathrm{~V}$. Data were acquired in full-scan mode with a mass range of 70 to $1,000 \mathrm{~m} / \mathrm{z}$ and a scan rate of $1 \mathrm{scan} / \mathrm{second}$. The samples were evaluated with Agilent MassHunter Quantitative Analysis (version B01.04) software.

Matrix effects and analytical performance. Matrix-matched standards were compared with standards prepared in acetonitrile to identify suppression or enhancement effects in the ionization step. Blank samples of creeping bentgrass verdure $(0.5 \mathrm{~g})$ that had no previous exposure to fungicide other than chlorothalonil (Daconil Ultrex; Syngenta Crop Protection) were spiked with the standard solution mixture $\left(1 \mu \mathrm{g} \mathrm{g}^{-1}\right)$ and extracted using the same procedure previously described. Matrix effect (ME, \%) was determined from the following equation: $\mathrm{ME}=[$ (standard peak area in solvent/standard peak area in verdure $) \times 100$ ]. Recovery tests were replicated three times to determine relative standard deviation (RSD) values of the analytes in both matrices. For instrument calibration, linear regression analysis was performed using standard solutions spiked in acetonitrile at concentrations of $0.001,0.01$, $0.1,1,10$, and $100 \mu \mathrm{g} \mathrm{g}^{-1}$. Instrument limit of quantification (LOQ) for the method were estimated using a signal-to-noise ratio of 10 $(\mathrm{S} / \mathrm{N}=10)$ measured by peak-to-peak method at the lowest calibration level.

\section{Results}

Bioassay. Symptomatic patches associated with brown patch development originating from the point of inoculation were consist- ently observed on nonfungicide-treated control samples during the course of the experiments, indicating a valid bioassay. Periodic isolations from diseased turf plants and examination of fungal mycelium confirmed damage was the result of infection by $R$. solani. All fungicides effectively controlled brown patch on the first sampling date (day 0) but differed in terms of residual efficacy in subsequent samplings.

Equality of variance was observed among the generated RE proportions for azoxystrobin, metconazole, polyoxin $\mathrm{D}$, and pyraclostrobin, which allowed for pooling of the bioassay data for all six experiments. Conversely, ANOVA for flutolanil demonstrated significant heterogeneity of variance $(P=0.000)$ among experiments. Tukey's HSD test $(P=0.05)$ indicated flutolanil experiments $1,2,5$, and 6 were statistically similar whereas flutolanil experiments 3 and 4 were statistically similar. Therefore, two separate models were created to describe the apparent differences in residual efficacy for flutolanil (Fig. 1). Models based on a twoparameter Weibull distribution function provided a good fit for the bioassay data, with coefficients of determination of $R^{2}=0.74$ to 0.96 (Fig. 1).

Weibull curves described the decline in residual efficacy as well as rate of decline over the 21-day sampling period. Fungicides differed not only in the length of time before a decline in protection was noticed but also the rate of decay once a decline occurred (Fig. 1). Scale parameter $\alpha$ estimates indicate the point in which protection was compromised. Based on these $\alpha$ estimates, brown patch control began to diminish 2.0 to 9.4 days after application. Azoxystrobin was the first fungicide to demonstrate a decline in efficacy, followed by pyraclostrobin, metconazole, polyoxin $\mathrm{D}$, and flutolanil (Fig. 1). With regard to flutolanil, experiments initiated during June exhibited an earlier decline in efficacy compared with those initiated in July through October. Rate of fungicide decay, represented by the shape parameter $\beta$ estimates, from steepest to gradual were as follows: polyoxin $\mathrm{D}$, flutolanil experiments 3 and 4 , metconazole, pyraclostrobin, azoxystrobin, and flutolanil experiments $1,2,5$, and 6 . By the last sampling date (21 days after fungicide treatment), fungicide protection was virtually nonexistent for all treatments. Flutolanil and Polyoxin D provided the greatest and least amount of residual efficacy, respectively.

Statistical differences were observed among mean efficacy halflife values (Table 2), with means of 3.1 to 14.0 days. Based on efficacy half-life values, flutolanil protection was $1.6 \times$ longer for experiments started in July, August, September, and October compared with those conducted in June. Pyraclostrobin, metconazole, and azoxystrobin had statistically $(P=0.05)$ similar efficacy halflife values. Azoxystrobin and pyraclostrobin, which have the same biochemical mode action but differ in terms of phytomobility, did not exhibit any statistically significant $(P=0.05)$ differences based on efficacy half-life. The two fungicides classified as local penetrants, polyoxin $\mathrm{D}$ and pyraclostrobin, differed $(P=0.05)$ with regard to their levels of brown patch control based on efficacy half-life values of 3.1 and 5.2 days, respectively (Table 2). In all but the azoxystrobin experiments, greater amounts of fungicide applied to the turf canopy (Table 1) led to improved residual efficacy (Table 2).

Quantitative residue analysis. The QuEChERS multiresidue method provided acceptable chromatographic results that allowed for repeatable detection and quantification of fungicide residues in creeping bentgrass over a wide range of concentrations. Differences among ionization for the selected fungicides were negligible, yielding MEs between 96 and 109\% (RSD < 8\%). Azoxystrobin and pyraclostrobin demonstrated sensitivity enhancement whereas flutolanil, metconazole, and myclobutanil were suppressed when spiked into turf verdure. Standard curves were linear over the range of 0.001 to $100 \mu \mathrm{g} \mathrm{g}^{-1}$ with correlation coefficients $R^{2} \geq 0.995$ for all fungicides. LOQs for azoxystrobin, flutolanil, metconazole, and pyraclostrobin were $2.0,6.0,0.6$, and $2.0 \mathrm{ng} \mathrm{g}^{-1}$, respectively.

Given the sensitivity of the described method, all of the fungicide treatments were detectable in sufficiently high titers for quantification through the last sampling date (day 21). Initial recoveries (day 0) varied greatly among the fungicides (Fig. 2). This variation 
most likely reflects differences in application rates (Table 1). The average fungicides detected on day 0 for azoxystrobin, flutolanil, metconazole, and pyraclostrobin were 127, 1,433, 128, and $200 \mu \mathrm{g}$ $\mathrm{g}^{-1}$ of verdure. All fungicide treatments measured demonstrated a precipitous decline following application (Fig. 2). Almost all (99\%) of the initial detected azoxystrobin residue had dissipated from the turf canopy 10 days after application. Likewise, $99 \%$ of flutolanil and metconazole residues were dissipated by day 14 and pyraclostrobin by day 17 . The selected exponential decay model accurately $\left(R^{2} \geq 0.94\right)$ described fungicide dissipation overtime. Residue half-lives for the acropetal penetrant fungicides azoxystrobin, flutolanil, and metconazole were 1.0, 2.2, and 1.6 days, respectively. Pyraclostrobin, the only local penetrant measured,
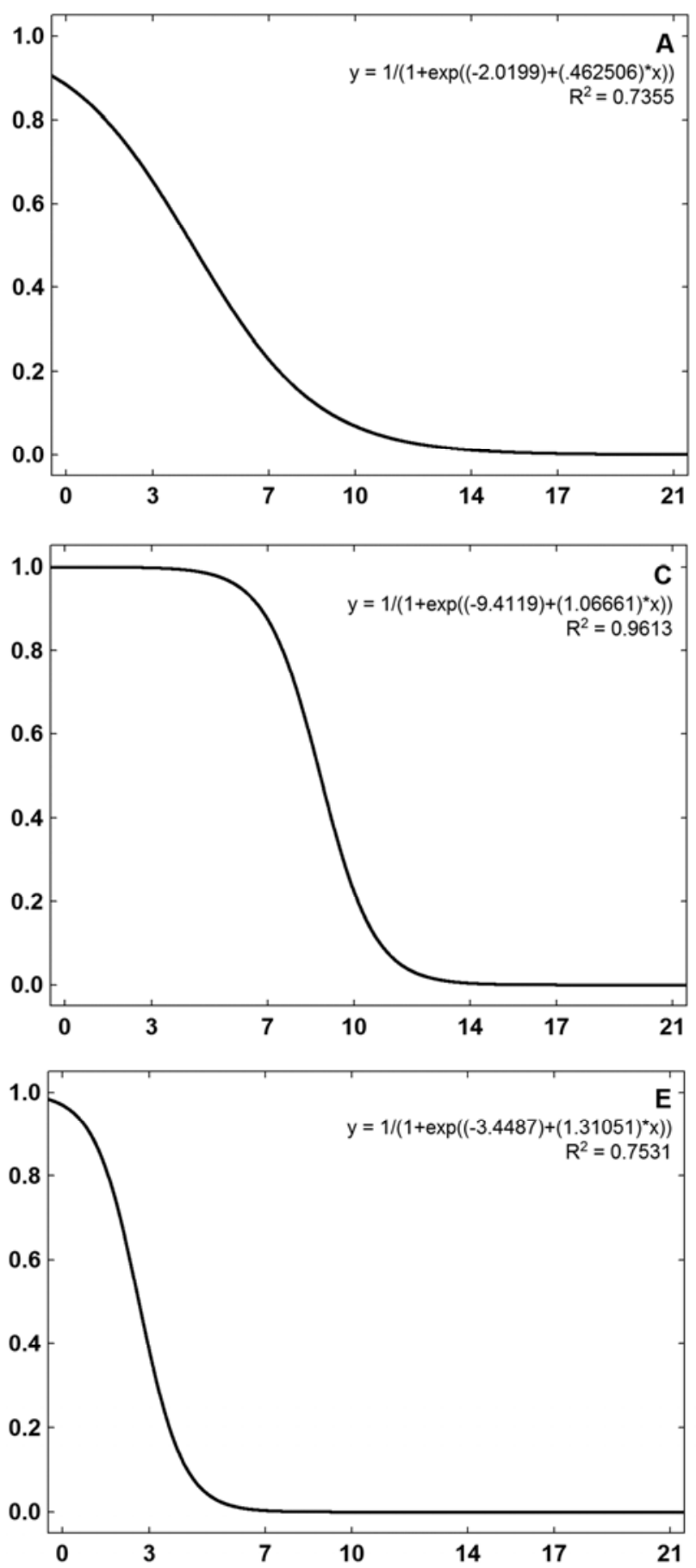

persisted slightly longer, with a half-life of 2.4 days. Decay rate constants $(k)$ from the exponential decay model indicate that azoxystrobin dissipated the fastest, followed by metconazole, flutolanil, and pyraclostrobin. Based on the first-order decay model, the concentration of azoxystrobin at which 50\% control was achieved during the bioassay was $5.0 \mu \mathrm{g} \mathrm{g}^{-1}$. Slightly more metconazole $\left(7.3 \mu \mathrm{g} \mathrm{g}^{-1}\right)$ and pyraclostrobin $\left(12.8 \mu \mathrm{g} \mathrm{g}^{-1}\right)$ were recovered at the same efficacy level. Flutolanil varied in concentration from 14.7 to $16.2 \mu \mathrm{g} \mathrm{g}^{-1}$ depending on the bioassay model.

\section{Discussion}

The bioassay results reported here suggest that creeping bentgrass is exposed to risk of brown patch outbreaks shortly (2 to 9
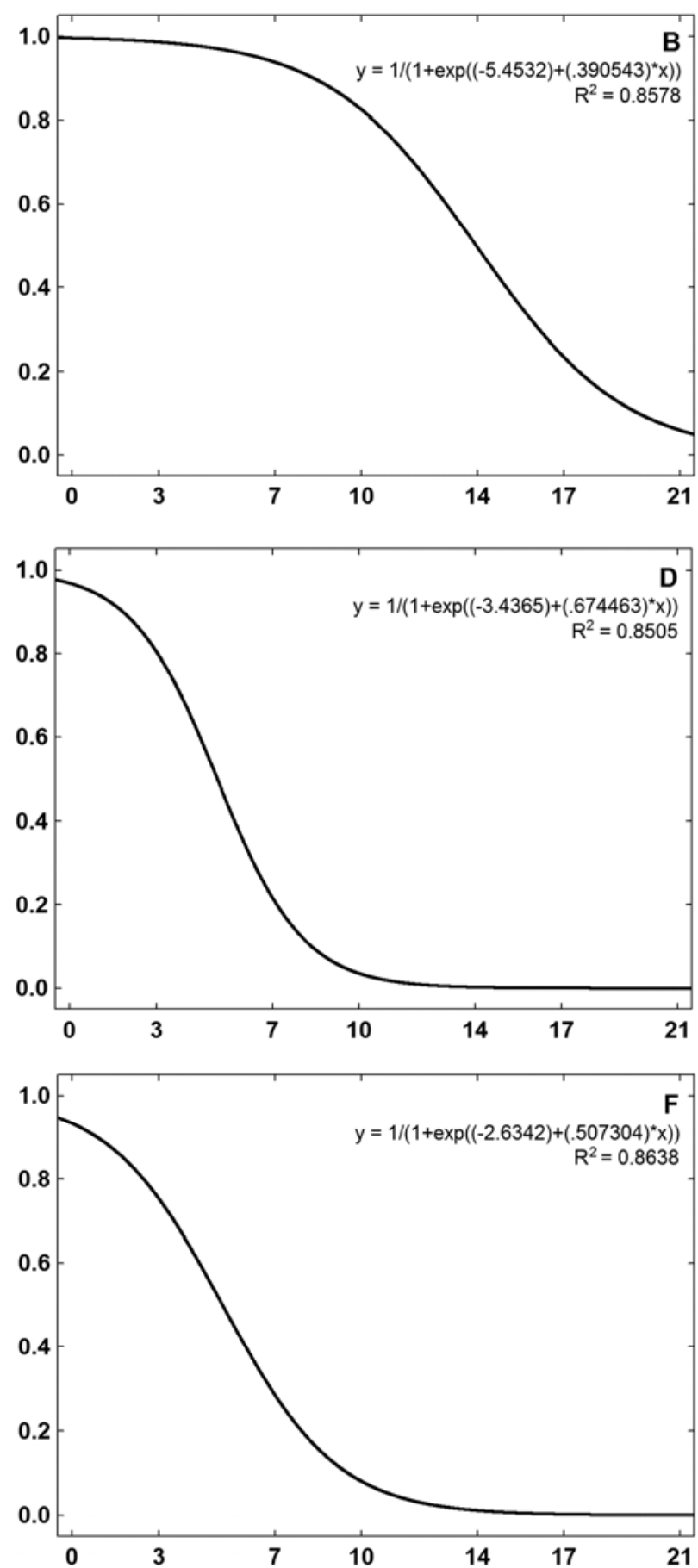

Fig. 1. Residual efficacy (RE) proportions for A, azoxystrobin; B, flutolanil experiments 1,2,5, and 6; C, flutolanil experiments 3 and 4; D, metconazole; E, polyoxin D; and F, pyraclostrobin where fit to a two-parameter Weibull function to describe the decline in efficacy over time. Experiments (1 to 6) were initiated 17 September 2010,12 October 2010, 8 June 2011, 22 June 2011, 6 July 2011, and 26 August 2011. 
days) after fungicide application when environmental conditions favor pathogen development. This loss in treatment efficacy is believed to be a result of a depletion of fungicide residues from the turf canopy, leaving plants vulnerable to infection. LC/TOF-MS results from 2011 demonstrated a similar reduction of fungicide residues from creeping bentgrass verdure, reinforcing conclusions drawn from bioassay results.

Consistent trends among the fungicides were observed during the bioassay over the course of 2010 and 2011. Fungicide residues were rapidly depleted from creeping bentgrass verdure following each application. Flutolanil had the greatest residual efficacy, followed by pyraclostrobin, metconazole, azoxystrobin, and polyoxin D. There are several possible explanations for the observed differences among treatments, one of which is the amount of fungicide applied to the verdure. It is reasonable to conclude that, where more fungicide is applied to turf, the targeted pathogen is more likely to encounter toxic levels of fungicide residue. As noted, flutolanil is labeled at a much higher rate relative to the other fungicides, and that could account for greater efficacy. Fungicide sensitivity could also account for differences in residual efficacy.

Table 2. Efficacy half-life values of five fungicides applied to creeping bentgrass fairways to control brown patch based upon a Weibull distribution function

\begin{tabular}{llc}
\hline Fungicide & Experiment $^{\mathbf{y}}$ & Efficacy half-life (days) $^{\mathbf{z}}$ \\
\hline Azoxystrobin & $1,2,3,4,5,6$ & $4.3 \mathrm{~cd}$ \\
Flutolanil & $1,2,5,6$ & $14.0 \mathrm{a}$ \\
Flutolanil & 3,4 & $8.8 \mathrm{~b}$ \\
Metconazole & $1,2,3,4,5,6$ & $5.1 \mathrm{c}$ \\
Polyoxin D & $1,2,3,4,5,6$ & $3.1 \mathrm{~d}$ \\
Pyraclostrobin & $1,2,3,4,5,6$ & $5.2 \mathrm{c}$ \\
\hline
\end{tabular}

${ }^{y}$ Experiments (1 to 6) were initiated 17 September 2010, 12 October 2010, 8 June 2011, 22 June 2011, 6 July 2011, and 26 August 2011.

${ }^{\mathrm{z}}$ Values followed by the same letter are not significantly different according to Tukey's honestly significant difference test $(P=0.05)$.
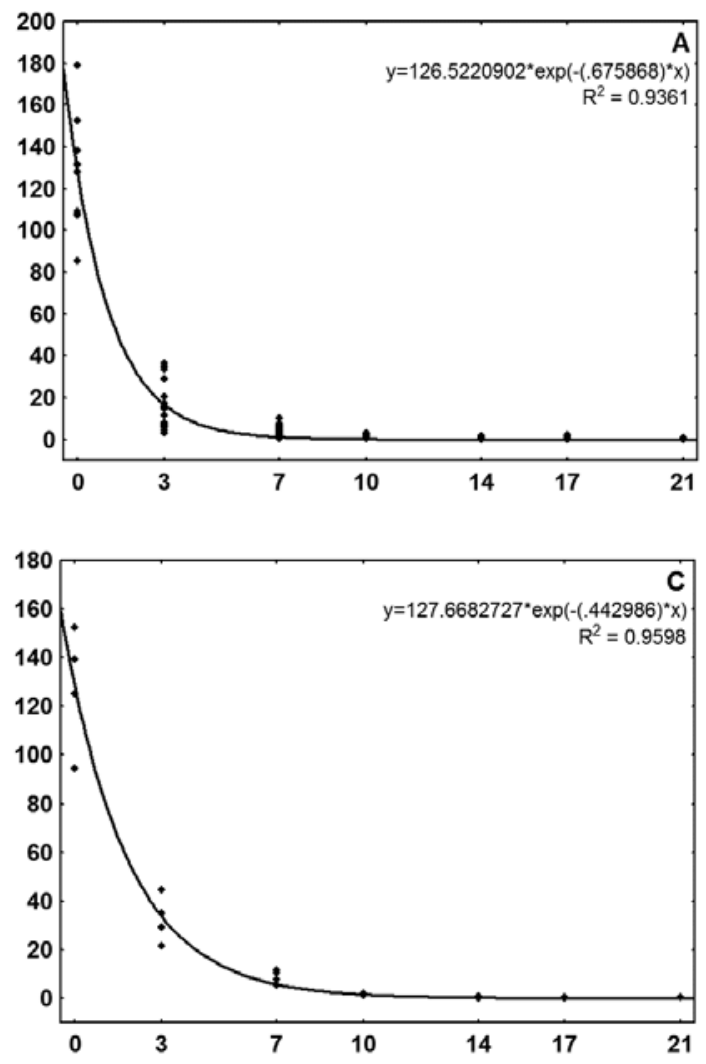

Fungicide intrinsic activity toward $R$. solani varies among fungicides with a unique mode of action, active ingredients within the same mode-of-action classification, and specific fungal isolates (12).

Flutolanil experiments initiated in June had much shorter residual efficacy compared with experiments conducted later during the growing season. Given that all samples were incubated under the same environmental conditions, inconsistency among flutolanil results is likely due to variation degradation processes in the field $(8,10,16,17,20-23)$. However, specific degradation factors responsible for the observed differences with regard to flutolanil residual efficacy among experiments are not known. It is also unclear as to why none of the other fungicides exhibited any significant variance among experiments. One possible reason for this lack of variation could be a result of the sensitivity detectable by the bioassay. Differences may have not been detectable for azoxystrobin, metconazole, polyoxin $\mathrm{D}$, and pyraclostrobin because they were applied at much lower rates relative to flutolanil. Those fungicides applied at lower rates may also have dissipated more rapidly in June, similar to flutolanil. However, the time between sampling may have been too long to detect any differences among experiments.

Previous field reports describe a much longer duration of brown patch control when using an effective fungicide $(4,18)$. In these reports, brown patch was evaluated using field trials where climatic fluctuations can lead to varying degrees of disease pressure. Increased duration of brown patch control in these reports could be a result of slight changes in environmental conditions, which can affect disease development and are not directly related to fungicide persistence in the turf. An advantage of the described bioassay is the ability to create high disease pressure conditions consistently over the course of the study. Maintaining consistent disease pressure over the course of 21 days in the field is probably not likely in most areas where creeping bentgrass is managed as a golf course fairway.

Another possible explanation for differences in residual efficacy between bioassay results and reported field observations is that
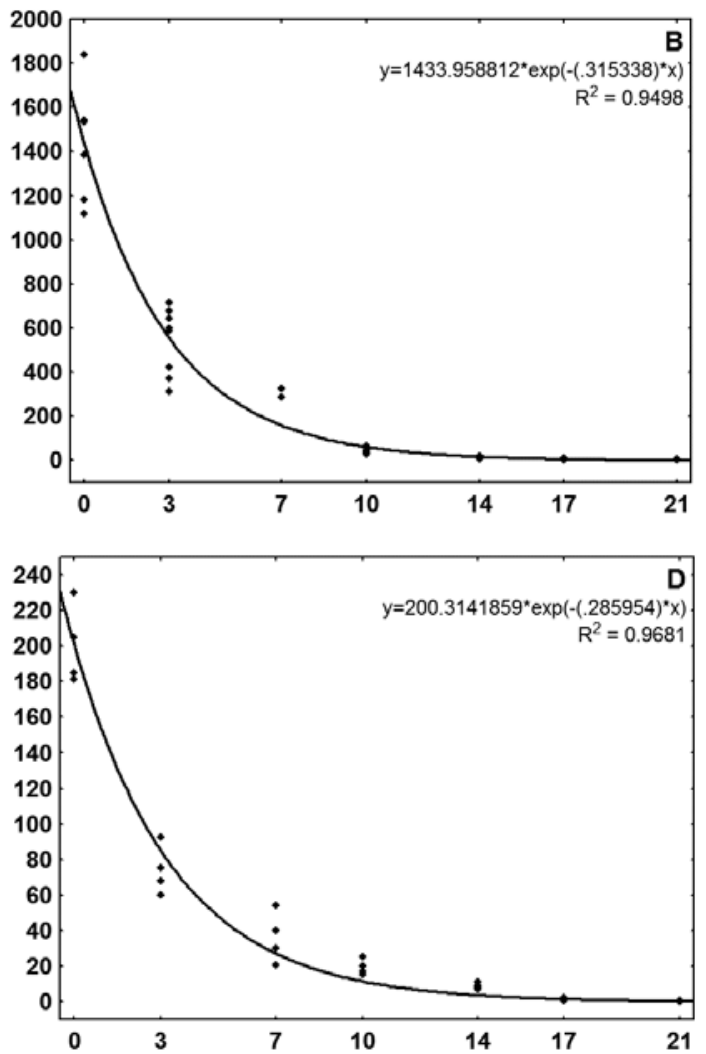

Fig. 2. Fungicide concentrations in creeping bentgrass verdure for A, azoxystrobin; B, flutolanil; C, metconazole; and D, pyraclostrobin in 2011 were fit to a first-order decay model. 
bioassay turf plugs were inoculated with a fresh culture of $R$. solani after each sampling date. It is important to note that, in fungicide field trials, fresh inoculum typically is not reintroduced in the same manner. This is noteworthy given the phytomobility characteristics of the fungicides used in the present study. Penetrant fungicides have the ability to suppress existing fungal infections and reduce endemic inoculum. The resulting suppression in pathogen growth achieved by an effective fungicide creates a lag period during which the surviving pathogen population slowly recovers to the point of symptom expression. Repeatedly introducing inoculum during the bioassay may have negated the impact of this lag period and resulted in the shorter duration of brown patch control.

Fungicide not intercepted by leaves and stems collects in the thatch, a tightly woven matrix of decomposing plant litter and living roots (8). Given the affinity of fungicide for the highly organic thatch layer, it is reasonable to question whether it serves as a fungicide reservoir, thereby increasing the duration of control in the field. In our bioassays, three of the fungicides (azoxystrobin, flutolanil, and metconazole) are acropetal penetrants. They are readily absorbed by roots and transported through xylem to leaves. If thatch served as a reservoir, then the bioassay and quantitative analysis would reflect the resupply of fungicide into the verdure. A more plausible explanation is that pathogen growth stops after active mycelia encounter and absorb fungicide associated with thatch. Similar to the situation where penetrant fungicides suppress fungal growth inside leaf tissues, it is likely that inoculum levels in the thatch are reduced to the point where many days pass before pathogen populations resume growth sufficient to cause symptoms.

In this research each fungicide was applied at a single rate, representing the high rate prescribed on product labels. Our interest emphasized dissipation of different classes of fungicides rather than effects of application rates. Also, we were faced with time and space constraints in the field and with the controlled environment chamber used in the bioassay. Depletion characteristics of different fungicide application rates warrant further investigation because efficacy and, perhaps, phytomobility are affected by the amount of fungicide deposited on turf.

Results from the present study help explain why fungicide treatments may not perform as expected during a given application interval and underscores the importance of applying fungicides in a timely manner for satisfactory disease control. Preventative applications that are delivered prematurely may dissipate prior to the arrival of environmental conditions that foster pathogen growth and promote disease outbreaks, leaving plants vulnerable to damage. The risk of disease-related damage as well as the cost associated with treatment reinforces the need to make informed management decisions concerning the use of fungicides. Turf managers should try to anticipate outbreaks and apply effective fungicides prior to disease development in order to achieve maximum fungicide performance but must also be aware of the rather short duration of effective residues in turf.

\section{Acknowledgments}

This research was supported, in part, by funds provided by the Midwest Regional Turf Foundation. We thank D. Bartlett, B. Cooper, A. Jannasch, D. Richmond, and S. Perry for their technical expertise.

\section{Literature Cited}

1. Anastassiades, M., Lehotay, S. J., Stajnbaher, D., and Schenck, F. J. 2003. Fast and easy multiresidue method employing acetonitrile extraction/partitioning and "Dispersive solid-phase extraction" for the determination of pesticide residues in produce. J. AOAC Int. 86:412-431.

2. Burpee, L. L. 1995. Interactions among mowing height, nitrogen fertility, and cultivar affect the severity of Rhizoctonia blight of tall fescue. Plant Dis. 79:721-726.

3. Dell, C. J., Throssell, C. S., Bischoff, M., and Turco, R. F. 1994. Estimation of sorption coefficients for fungicides in soil and turfgrass thatch. J. Environ. Qual. 23:92-96.

4. Fidanza, M. A., and Dernoeden, P. H. 1996. Brown patch severity in perennial ryegrass as influenced by irrigation, fungicide, and fertilizers. Crop Sci. 36:1631-1638.

5. Fidanza, M. A., and Dernoeden, P. H. 1996. Interaction of nitrogen source, application timing, and fungicide on Rhizoctonia blight in ryegrass. HortScience 31:389-392.

6. Frederick, E. K., Bischoff, M., Throssell, C. S., and Turco, R. F. 1994. Degradation of chloroneb, triadimefon, and vinclozolin in soil, thatch, and grass clippings. Bull. Environ. Contam. Toxicol. 53:536-542.

7. Frederick, E. K., Throssell, C. S., Bischoff, M., and Turco, R. F. 1996. Fate of vinclozolin in creeping bentgrass turf under two application frequencies. Bull. Environ. Contam. Toxicol. 57:391-397.

8. Gardner, D. S., and Branham, B. E. 2001. Effect of turfgrass cover and irrigation on soil mobility and dissipation of mefenoxam and propiconazole. J. Envrion. Qual. 30:1612-1618.

9. Gardner, D. S., Branham, B. E., and Lickfeldt, D. W. 2000. Effect of turfgrass on soil mobility and dissipation of cyproconazole. Crop Sci. 40:1333-1339.

10. Ghosh, R. K., and Singh, N. 2009. Effect of organic manure on sorption and degradation of azoxystrobin in soil. J. Agric. Food Chem. 57:632-636.

11. Horst, G. L., Shea, P. J., Christians, N., Miller, D. R., Stuefer-Powell, C., and Starrett, S. K. 1996. Pesticide dissipation under golf course fairway conditions. Crop Sci. 36:362-370.

12. Kataria, H. R., Hugelshofer, U., and Gisi, U. 1991. Sensitivity of Rhizoctonia species to different fungicides. Plant Pathol. 40:203-211.

13. Latin, R. 2006. Residual efficacy of fungicides for control of dollar spot on creeping bentgrass. Plant Dis. 90:571-575.

14. Latin, R. 2011. A Practical Guide to Turfgrass Fungicides. American Phytopathological Society, St. Paul, MN.

15. Lehotay, S. J. 2007. Determination of pesticide residues in foods by acetonitrile extraction and partitioning with magnesium sulfate: collaborative study. J. AOAC Int. 90:485-520.

16. Magri, A., and Haith, D. A. 2009. Pesticide decay in turf: a review of processes and experimental data. J. Environ. Qual. 38:4-12.

17. Rice, P. J., Horgan, B. P., and Rittenhouse, J. L. 2010. Pesticide transport with runoff from creeping bentgrass turf: relationship of pesticide properties to mass transport. Environ. Toxicol. Chem. 29:1209-1214.

18. Settle, D., Fry, J., and Tisserat, N. 2001. Effects of irrigation frequency on brown patch in perennial ryegrass. Int. Turfgrass Soc. Res. J. 9:710-714.

19. Sigler, W. V., Reicher, Z., Throssell, C., Bischoff, M., and Turco, R. F. 2003. Sorption and degradation of selected fungicides in the turfgrass canopy. Water Air Soil Pollut. 142:311-326.

20. Suzuki, T., Kondo, H., Yaguchi, K., Maki, T., and Suga, T. 1998. Estimation of leachability and persistence of pesticides at golf courses from pointsource monitoring and model to predict pesticide leaching to groundwater. Environ. Sci. Technol. 32:920-929.

21. Thom, E., Ottow, J. C. G., and Benckiser, G. 1997. Degradation of the fungicide difenoconazole in a silt loam soil as affected by pretreatment and organic amendment. Environ. Pollut. 96:409-414.

22. Vincelli, P. 2004. Simulations of fungicide runoff following applications for turfgrass disease control. Plant Dis. 88:391-396.

23. Wu, L., Liu, G., Yates, M. V., Green, R. L., Pacheco, P., Gan, J., and Yates, S. R. 2002. Environmental fate of metalaxyl and chlorothalonil applied to a bentgrass putting green under southern California climatic conditions. Pest Manage. Sci. 58:335-342.

24. Zhao, L., and Stevens, J. 2009. Analysis of pesticide residues in spinach using Agilent SampliQ QuEChERS AOAC kit by LC/MS/MS detection. Agilent Technol. Publ. 5990-4248EN. 